\title{
REDUÇÃO DA VIABILIDADE DE OVOS DE HELMINTOS EM LODO DE ESGOTO DOMÉSTICO CALEADO
}

\author{
Maike Rossmann ${ }^{1}$, Danielle Biajoli Vieira², Fabiana Ferreira Avelar ${ }^{3}$, Antônio Teixeira de Matos ${ }^{4}$
}

\section{RESUMO}

O aproveitamento agrícola do lodo de esgoto apresenta-se como uma alternativa viável para sua disposição final. Entretanto, para sua reutilização e destinação correta, é necessária sua estabilização. Os objetivos com a condução deste trabalho foram: quantificar a concentração de ovos de helmintos viáveis no lodo; avaliar a sobrevivência desses ovos no lodo submetido a diferentes tempos de caleação e classificar o lodo, segundo a Resolução CONAMA no 375, no que se refere a uso agrícola. O experimento foi constituído por três tratamentos e quatro repetições. Os tratamentos foram: caleação do lodo de esgoto com dose de cal necessária a manutenção do $\mathrm{pH}$ acima de 12, por 72 h; caleação do lodo de esgoto com dose de cal necessária a manutenção do $\mathrm{pH}$ acima de 12, por $2 \mathrm{~h}$, e lodo de esgoto sem adição de cal. Para comparar a concentração de ovos de helmintos entre os tratamentos foram ajustados modelos lineares generalizados, utilizando distribuição de erro Poisson corrigida para Quase-Poisson, e submetidos ao teste F. A caleação do lodo por 2 e 72 h promoveu a inativação de 93,75 e 99,32\% dos ovos de helmintos, sendo o lodo, após o tratamento, classificado como Classe B e Classe A, respectivamente. Do ponto de vista sanitário, o tempo de $72 \mathrm{~h}$ forneceu um lodo mais seguro para uso agrícola.

Palavras-chave: caleação do lodo, higienização, micro-organismos patogênicos

\section{ABSTRACT}

\section{REDUCTION OF THE VIABILITY OF HELMINTH EGGS IN LIME-TREATED SEWAGE SLUDGE}

The agricultural use of sewage sludge is presented as one of the most viable alternatives for its disposal. However, for its adequate reuse it must first be stabilized. The aim of this study was to determine the concentration of viable helminth eggs present in sewage sludge, to evaluate the survival of the eggs in the sludge submitted to different reaction times with lime and classify the sludge, according to the CONAMA 375 Resolution, regarding its agricultural use. The experiment consisted of three treatments and four replications. The treatments consisted of: reaction of sewage sludge with the lime dose required to maintain the $\mathrm{pH}$ greater than 12 for $72 \mathrm{~h}$, reaction of sewage sludge with the lime dose required to maintain the $\mathrm{pH}$ greater than 12 for $2 \mathrm{~h}$, and sewage sludge without addition of lime. To compare the concentration of helminth eggs between treatments, generalized linear models were adjusted using the Poisson error distribution corrected for Quasi-Poisson, and submitted to the F-test. The sewage sludge treated for $2 \mathrm{~h}$ and $72 \mathrm{~h}$ promoted the inactivation of 93.75 and $99.32 \%$ of helminth eggs, where after treatment the sludge was classified as Class B and Class A, respectively. From a sanitary view the time of $72 \mathrm{~h}$ resulted in a safer sludge for agricultural use.

Keywords: lime-treated sewage sludge, hygienization, pathogenic microorganisms.

\section{Recebido para publicação em 16/04/2013. Aprovado em 07/06/2013.}

1 - Bióloga, D.S. em Eng. Agrícola, Pesquisadora visitante no Rothamsted Research / Harpenden-UK, e-mail: maike.rossmann@ufv.br

2 - Eng. Ambiental, M.S.em Eng. Agrícola, Analista de relacionamento com comunidades (Anglo American), e-mail: danibiajoli@yahoo.com.br

3 - Engenheira Agrônoma, D.S. em Engenharia Agrícola, e-mail: fabiana.avelar@ufv.br

4 - Eng. Agrícola, D.S. em Solos e Nutrição de Plantas, Professor Associado DEA-UFV / Viçosa-MG, e-mail: atmatos@ufv.br 


\section{INTRODUÇ̃̃O}

O destino final do lodo de esgoto gerado nas estações de tratamento tem se apresentado como um dos principais problemas na cadeia "coletatratamento-disposição final", uma vez que este apresenta grande potencial de veiculação de micro-organismos patogênicos, metais pesados e moléculas orgânicas. Em termos de poluição microbiológica, lodos de esgoto frequentemente contêm vários agentes patogênicos como ovos de helmintos, cistos de protozoários, bactérias e vírus entéricos (CAPIZZI-BANAS et al., 2004).

$\mathrm{O}$ aproveitamento agrícola do lodo de esgoto se apresenta como uma das alternativas mais viáveis para disposição final deste resíduo, devido aos benefícios que ele pode trazer ao solo. A riqueza de nutrientes e de matéria orgânica presente em tal rejeito permite, quando disposto no solo em dose adequada, o aumento na absorção de nutrientes pelas culturas, com consequente ganho de produtividade. O maior obstáculo à aplicação de lodo em áreas agrícolas é o risco sanitário, que embora seja pequeno, tem sido objeto de preconceito, mais por desconhecimento do que, propriamente, em decorrência de seu potencial risco como causador de doenças (MATOS, 2008).

Os ovos de helmintos, pela sua maior capacidade de sobrevivência, tornam-se o indicador mais importante para a avaliação das condições sanitárias do lodo (PINTO, 2001; CAPIZZI-BANAS et al., 2004). A sobrevivência no lodo em temperaturas de 20 a $30{ }^{\circ} \mathrm{C}$ pode ser de meses. No solo, alguns ovos podem permanecer viáveis de dois até sete anos, em condições de sombra e adequado conteúdo de água (WHO, 2006; JIMENÉZ, 2007).

Para a reutilização e a destinação correta dos lodos de esgoto, é necessário que esse resíduo passe por um processo de estabilização, denominado higienização. São vários os processos de tratamento adotados para a higienização do lodo: caleação (inertização pela cal); pasteurização; radiação beta, gama e solar; exposição do lodo a elevadas temperaturas (secagem térmica); digestão aeróbia; digestão anaeróbia; hipercloração; compostagem (SPINOSA, 2011; KELESSIDIS; STASINAKIS, 2012) e vermicompostagem (SINHA et al., 2010).

A caleação consiste na mistura da cal virgem
$(\mathrm{CaO})$ ou cal hidratada $\left(\mathrm{Ca}(\mathrm{OH})_{2}\right)$ ao lodo em proporções que variam de 30 a $50 \%$ da massa de lodo seco (PINTO, 2001) e apresenta como vantagens o fato de ser de baixo custo, de fácil aplicabilidade e eficiente, gerando um produto alcalino, de alta reatividade, em condições de corrigir a acidez do solo (HUE, 1992). Além disso, a caleação minimiza odores e proporciona estabilidade química ao lodo de esgoto (MATOS, 2008).

O processo de desinfecção por meio da caleação, com a inativação ou destruição da maior parte dos patógenos, ocorre devido à alteração da temperatura (notadamente quando se faz uso de cal virgem), à mudança no $\mathrm{pH}$ e à ação da amônia, resultante de transformação do nitrogênio em meio fortemente alcalino (ANDREOLI; FERNANDES, 1999). Entretanto, para se obter uma adequada higienização, há que se respeitar os períodos de carência, que são variáveis segundo a dosagem utilizada de cal (ILHENFELD et al., 1999). Segundo a legislação nacional, Resolução CONAMA n ${ }^{\circ}$ 375 (2006), e alguns autores (U.S.EPA, 2003 e METCALF; EDDY, 2003), a inertização do lodo pela adição de cal envolve a adição de quantidades suficientes para alcançar e manter o $\mathrm{pH}$ acima de 12 pelo período mínimo de $2 \mathrm{~h}$. De acordo com Fernandes (2000), para se obter eficiente remoção de patógenos, o $\mathrm{pH}$ do resíduo deve permanecer acima de 12, por um período de $72 \mathrm{~h}$.

Visando a obtenção de dados que possam colaborar com outros estudos, no presente trabalho tiveram-se, como objetivos: (i) quantificar a concentração de ovos de helmintos viáveis presentes no lodo de esgoto; (ii) avaliar a sua sobrevivência no lodo submetido a diferentes tempos de caleação e; (iii) classificar o lodo de esgoto, segundo a Resolução CONAMA n ${ }^{\circ} 375$, quanto ao seu uso agrícola.

\section{MATERIAL E MÉTODOS}

O lodo de esgoto utilizado neste trabalho foi proveniente da Estação de Tratamento de Esgoto de Muriaé - ETE José Cirilo. Por ocasião da coleta das amostras, o lodo coletado já se encontrava há 75 dias em leito de secagem.

Para higienização pelo processo de caleação, o lodo foi previamente seco ao ar, destorroado 
e peneirado (peneira $2 \mathrm{~mm}$ ). As doses de cal hidratada, $\mathrm{Ca}(\mathrm{OH})_{2}$, necessárias para manter o $\mathrm{pH}$ do lodo acima de 12 , por $2 \mathrm{~h}$ e por $72 \mathrm{~h}$, foram obtidas a partir das curvas de incubação do lodo com a cal. Para isso, diferentes doses de cal hidratada $\left(0,25,50,100,150,200\right.$ e $\left.250 \mathrm{~kg} \mathrm{~m}^{-3}\right)$ foram adicionadas ao lodo. A mistura recebeu água até ser atingida a capacidade de campo, para favorecimento da reação. Após 2 e $72 \mathrm{~h}$ de efetuada a mistura, o $\mathrm{pH}$ do material foi medido em suspensão preparada com solução $\mathrm{CaCl}_{2} 0,01$ mol L-1 (MATOS, 2008), sendo obtida uma curva para cada tempo de reação pós-mistura. As doses de cal hidratada necessárias para manter o $\mathrm{pH}$ do lodo acima de 12 , por 2 e por $72 \mathrm{~h}$, foram $40,0 \mathrm{~kg}$ $\mathrm{m}^{-3}$ e $71,2 \mathrm{~kg} \mathrm{~m}^{-3}$, respectivamente.

O experimento foi composto por três tratamentos e quatro repetições. Os tratamentos foram: (i) caleação do lodo de esgoto com dose de cal necessária a manutenção do $\mathrm{pH}$ acima de 12 por 72 h; (ii) caleação do lodo de esgoto com dose de cal necessária a manutenção do $\mathrm{pH}$ acima de 12 por $2 \mathrm{~h}$ e; (iii) lodo de esgoto sem adição de cal (controle).

A contagem de ovos de helmintos viáveis nas amostras de lodo de esgoto foi realizada segundo a metodologia descrita por Meyer et al. (1978). O lodo de esgoto foi misturado a uma solução de hipoclorito de sódio $50 \%$, permanecendo em repouso durante 50 min. Em seguida, a mistura foi transferida para tubos de centrífuga, sendo o sobrenadante descartado e o sedimento lavado, diversas vezes, com solução Tween 80 0,1\%. Após a etapa de lavagens, foi adicionado solução de $\mathrm{ZnSO}_{4}$ densidade 1,18 ao sedimento e este foi novamente centrifugado. Antes da recuperação do sobrenadante aguardou-se 3 min para a flotação dos ovos. O sobrenadante foi filtrado através de membrana Milipore $0,45 \mathrm{~mm}$ de porosidade. O sedimento da membrana foi raspado e colocado em placa de Petri contendo solução de $\mathrm{H}_{2} \mathrm{SO}_{4} 0,1 \mathrm{~mol}_{c} \mathrm{~L}^{-1}$. A placa contendo os ovos recuperados foi envolvida em papel alumínio e incubada no escuro, em estufa a $28{ }^{\circ} \mathrm{C}$, durante 28 dias. Após esse período, utilizou-se a câmara de Sedgwick-Rafter para a contagem dos ovos viáveis de helmintos, empregando-se uma alíquota de $1 \mathrm{~mL}$ da amostra contida na placa. A contagem dos ovos de helmintos foi realizada com o auxílio de um Microscópio biológico binocular da marca Olympus, modelo CX31, utilizando-se objetiva de 40x.

Para comparar a concentração de ovos de helmintos nos materiais submetidos aos diferentes tratamentos, foram ajustados modelos lineares generalizados (GLM). Os modelos foram submetidos à análise de resíduos para verificar a adequação dos mesmos à disposição de erro assumida. Foi utilizada distribuição de erro Poisson, corrigida para Quase-Poisson, já que os dados eram sobredispersos, sendo os modelos submetidos ao teste F (CRAWLEY, 2002). A simplificação do modelo foi realizada utilizando teste $\mathrm{F}$ até a obtenção do modelo mínimo adequado (MMA), com o menor número de categorias possíveis para explicar os resultados. As análises foram realizadas com o auxílio do software R 2.6.2 (R DEVELOPMENT CORE TEAM, 2008).

\section{RESULTADOS E DISCUSSÃO}

A densidade de ovos no lodo de esgoto foi influenciada pela adição de cal hidratada $\left(\mathrm{F}_{1,10}=\right.$ 41.382; $\mathrm{P}<0,0001$ ) (Quadro 1). Tendo em vista que a cal hidratada, $\mathrm{Ca}(\mathrm{OH})_{2}$, não proporciona significativo aumento na temperatura do lodo de esgoto (PINTO, 2001), acredita-se que o processo de desinfecção por meio da caleação tenha ocorrido essencialmente devido à mudança no $\mathrm{pH}$ e à ação da amônia, formada com a transformação do nitrogênio contido no lodo.

Quadro 1. Modelos lineares generalizados para testar o número de ovos viáveis de helmintos sob a adição de cal hidratada.

\begin{tabular}{ccccccc}
\hline $\begin{array}{c}\text { Variável } \\
\text { resposta }\end{array}$ & $\begin{array}{c}\text { Variável } \\
\text { explicativa* }\end{array}$ & g.l. & Deviância & g.l. residual & $\begin{array}{c}\text { Deviância } \\
\text { residual }\end{array}$ & P (>F) \\
\hline \multirow{2}{*}{ Número de ovos } & $\begin{array}{c}\text { Modelo Nulo } \\
\text { Caleação }\end{array}$ & 1 & 194.64 & 10 & 234.513 & \\
& * & & 11 & 39.871 & $7.51 \mathrm{e}-05$ \\
\hline
\end{tabular}

* variável explicativa obtida do modelo mínimo adequado $(\mathrm{p}<0.05)$, sendo os modelos ajustados à distribuição de erro Quase-Poisson. 
A análise do lodo de esgoto sem adição de cal (controle) indicou a presença de, aproximadamente, 28 ovos de helmintos viáveis por grama de sólidos totais (Quadro 2). Torna-se importante ressaltar que o número de ovos encontrado no grupo controle pode não corresponder ao número de ovos presente no lodo de esgoto bruto, pois a permanência do lodo em leito de secagem permite branda desinfecção, decorrente tanto da elevação da temperatura como da redução no conteúdo de água do material (GONÇALVES et al., 2001). A caleação do lodo com dose de cal necessária à manutenção do $\mathrm{pH}$ acima de 12 , por $72 \mathrm{~h}$, proporcionou contagem próxima a zero.

Quadro 2. Número médio de ovos viáveis de helmintos nas amostras de lodo de esgoto sem adição de cal (controle) e submetidas à caleação com dose de cal necessária a manutenção do $\mathrm{pH}$ acima de 12, por $2 \mathrm{~h}$, e necessária a manutenção do $\mathrm{pH}$ acima de 12, por $72 \mathrm{~h}$.

\begin{tabular}{lc}
\hline Tratamento & Média* \\
\hline Controle & $27,99 \mathrm{~A}$ \\
Caleação por $2 \mathrm{~h}$ & $1,75 \mathrm{~B}$ \\
Caleação por $72 \mathrm{~h}$ & $0,19 \mathrm{~B}$ \\
\hline
\end{tabular}

* número de ovos viáveis por grama de sólidos totais. Médias seguidas com a mesma letra não diferem entre si pelo teste F.

As contagens de ovos viáveis de helmintos nos lodos de esgoto caleados com dose que proporcionou $\mathrm{pH}$ acima de 12 por 2 e por $72 \mathrm{~h}$ não foram diferentes, sendo, porém, inferiores à obtida na amostra submetida ao tratamento controle (Quadro 2). A redução na viabilidade dos ovos foi de $93,75 \%$ e $99,32 \%$ para a caleação por 2 h e 72 h, respectivamente. Maya et al. (2012), avaliando a inativação de quatro nematóides (Ascaris lumbricoides, Ascaris suum, Toxocara canis e Trichuris trichiura) e dois céstodos (Hymenolepis nana e Taenia solium), alcançaram inativação de todas as espécies com a alcalização do lodo a $\mathrm{pH}$ de 12,7 por um período de 19 dias, a $45^{\circ} \mathrm{C}$ e $10 \%$ de conteúdo de água no material. Farzadkia et al. (2009) avaliaram a estabilização do biossólido proveniente do tratamento de águas residuárias municipais com diferentes doses de cal e obtiveram valores de inativação de ovos de helmintos variando de 42,68 a $57,64 \%$. Jensen et al. (2009) estudaram a inativação de ovos de helmintos em excretas humanas submetidas à aplicação de doses de calcário entre 0 e $11 \%$ da massa de lodo seco. Os autores verificaram que, independentemente do $\mathrm{pH}$ inicial, que variou de 9,4 a $11,6,99 \%$ dos ovos se tornaram inviáveis entre 105 e 117 dias de armazenamento do lodo e $97 \%$ dos ovos após 88 dias de armazenamento.

Em geral, para a aplicação segura de águas residuárias, excretas e lodos, é sugerido, como limite, a contagem de um ovo de helminto por litro de água ou um ovo de helminto por grama de sólidos secos totais (WHO, 2006). Entretanto, o interesse na aplicação desses limites e na identificação de processos de inativação eficazes não são os mesmos em todo o mundo, uma vez que diferentes países e regiões enfrentam problemas diferentes. Por exemplo, a quantidade de ovos de helmintos presentes em águas residuárias e lodos de esgoto em países em desenvolvimento variam entre 70-300 ovos por litro e 70-735 ovos por grama de sólidos totais, respectivamente (STRAUSS et al., 2003; JIMÉNEZ; WANG, 2006; TRÖNNBERG et al., 2010); em comparação, países desenvolvidos apresentam concentrações entre 1-9 ovos por litro e 2-13 ovos por grama de sólidos totais (JIMÉNEZ; WANG, 2006).

A Resolução CONAMA no 375 (2006), que define critérios e procedimentos para o uso agrícola de lodos de esgoto gerados em estações de tratamento de esgoto sanitário e seus produtos derivados, estabelece como limite máximo de concentração para um lodo Classe A valor menor que 0,25 ovo viável de helminto por grama de sólidos totais. Para um lodo Classe B, a Resolução estabelece valor menor que 10 ovos viáveis de helmintos por grama de sólidos totais. De acordo com os resultados apresentados na Tabela 2, o lodo de esgoto em estudo, quando submetido ao processo de caleação por $2 \mathrm{~h}$ e por $72 \mathrm{~h}$, foi enquadrado como Classe B e Classe A, respectivamente. Segundo consta na referida Resolução, os lodos de esgoto enquadrados como Classe A poderão ser utilizados na fertilização do solo de quaisquer culturas agrícolas, exceto em pastagens e cultivo de olerícolas, tubérculos, raízes 
e culturas inundadas, bem como as demais culturas cuja parte comestível entre em contato com o solo. Já os lodos enquadrados como Classe B, têm sua aplicação restrita ao cultivo de café, silvicultura, culturas para produção de fibras e óleos, com a aplicação mecanizada, em sulcos ou covas, e seguida de incorporação.

Entre os processos de tratamento sugeridos pela Agência de Proteção Ambiental dos Estados Unidos (U.S. EPA) para a obtenção de um lodo de esgoto Classe A estão os que proporcionam a elevação no $\mathrm{pH}$ do material. Considerando-se a redução do número de ovos de helmintos a menos de 1 ovo viável por 4 gramas dos sólidos totais (U.S. EPA, 2003), verifica-se que o lodo de esgoto caleado por $72 \mathrm{~h}$ seria adequado para o uso em pastagens e terras aráveis em que forrageiras são cultivadas, sendo o acesso ao público não restrito.

Com base nos resultados alcançados, pode-se inferir que a adição de cal no lodo deve ter reduzido, também e de forma eficiente, a presença dos demais micro-organismos patogênicos. Apesar de, no presente estudo, não ter sido avaliado variáveis como os limites de coliformes termotolerantes, Salmonella e vírus, a elevação do $\mathrm{pH}$ do lodo provoca alterações significativas de natureza coloidal no protoplasma celular e produz um ambiente inóspito para a sobrevivência desses indivíduos. Além disso, o solo é um ambiente geralmente muito hostil à sobrevivência de patógenos. Segundo Lu et al. (2012), caso sejam estabelecidos processos adequados de precaução, os riscos de patógenos em biossólidos são mínimos. Segundo os autores, quando biossólidos são aplicados na superfície do solo, dessecação e luz ultravioleta são responsáveis pela inativação de patógenos. Quando biossólidos são incorporados no solo, a sobrevivência dos patógenos é afetada por fatores como $\mathrm{pH}$, temperatura, escassez de material orgânico, presença de toxinas produzidas por plantas e outros organismos, predação e competição.

Considerando-se que a maior parte dos solos brasileiros é ácida, a aplicação de corretivos, para aumentar o seu potencial produtivo, faz-se necessária (VELOSO et al., 1992). Portanto, o uso de lodo caleado pode substituir a aplicação de calcário nos solos, concorrendo para aumento de sua fertilidade. Firmando o dito, Fia et al. (2005) fizeram a caracterização química do solo, antes e após a aplicação de lodo de esgoto caleado, verificando melhoria na sua fertilidade, com aumento na disponibilidade de nutrientes, do $\mathrm{pH}$ e, com isso, aumento na produtividade do milho.

Diante do exposto, pode-se afirmar que a caleação seguida da aplicação do lodo tratado no solo deve ser considerada importante alternativa para destinação final desses resíduos, já que concorre para redução nos seus custos. Além disso, apresenta-se como um processo de disposição final adequado do ponto de vista econômico e ambiental, uma vez que promove a redução de gastos com fertilizantes e diminuição de áreas que seriam necessárias para o armazenamento e destinação final dos lodos (aterros).

\section{CONCLUSÕES}

- A análise do lodo de esgoto sem adição de cal (controle) indicou a presença de, aproximadamente, 28 ovos de helmintos viáveis por grama de sólidos totais. A caleação do lodo com dose de cal necessária à manutenção do $\mathrm{pH}$ acima de 12, por 2 e 72 horas, proporcionou contagem de, aproximadamente, 2 e zero ovos de helmintos viáveis por grama de sólidos totais, respectivamente.

- A caleação do lodo por 2 e $72 \mathrm{~h}$ promoveu a inativação de 93,75 e 99,32\% dos ovos de helmintos, sendo o lodo, após o tratamento, classificado como Classe B e Classe A, respectivamente.

\section{AGRADECIMENTOS}

Os autores agradecem ao Conselho Nacional de Desenvolvimento Científico e Tecnológico (CNPq) e à Coordenação de Aperfeiçoamento de Pessoal de Nível Superior (Capes) pelas bolsas de mestrado e doutorado concedidas.

\section{REFERÊNCIAS BIBLIOGRÁFICAS}

ANDREOLI, C.V.; FERNANDES, F. Manual prático para a compostagem de biossólidos. Rio de Janeiro: ABES, 1999. 84p. 
CAPIZZI-BANAS, S.; DELOGE, M.; REMY, M.; SCHWARTZBROD, J. Liming as an advanced treatment for sludge sanitisation: helminth eggs elimination - Ascaris eggs as model. Water Research, v.38, n.14-15, p.3251-3258, 2004.

BRASIL. Conselho Nacional do Meio Ambiente (CONAMA). Resolução ${ }^{\circ}$ 375, de 29 de agosto de 2006. Define critérios e procedimentos para o uso agrícola de lodos de esgoto gerados em estações de tratamento de esgoto sanitário e seus produtos derivados, e dá outras providências. Diário Oficial da República Federativa do Brasil, Brasília, DF, 30 ago. 2006.

CRAWLEY, M. Statistical computing: An introduction to data analysis using S-Plus. Jonh Wiley \& Sons Inc., Baffins Lane, 2002. 761p.

FARZADKIA, M.; JAAFARZADEH, N.; ASL, L. L. Optimization of bacteriological quality of biosolids by lime addition. Iranian Journal of Environmental Health Science \& Engineering, v.6, n.1, p.29-34, 2009.

FERNANDES, F. Estabilização e higienização de biossólidos. In: BETTIOL, W.; CAMARGO, O. A. Impacto Ambiental do uso agrícola do lodo de esgoto. Jaguariúna: EMBRAPA Meio Ambiente, 2000. p.45-67.

FIA, R.; MATOS, A.T.; AGUIRRE, C.I. Características químicas de solo adubado com doses crescentes de lodo de esgoto caleado. Engenharia na Agricultura, v. 13, n.4, p. 287299, 2005.

GONÇALVES, R. F.; LUDUVICE, M.; VON SPERLING, M. Remoção da umidade de lodos de esgotos. In: ANDREOLI, C.V.; VON SPERLING, M.; FERNANDES. F. Lodos de esgotos: tratamento e disposição final. Belo Horizonte: DESA/UFMG, SANEPAR, 2001. p.159-259.

HUE, N.V. Correcting soil acidity of a highly weathered Ultisol with chicken manure and sewage sludge. Communications in Soil Science and Plant Analysis, v.23, n.3-4, p.241-264, 1992.
ILHENFELD, R.G.; ANDREOLI, C.A.; LARA, A.I. Higienização do Lodo de Esgoto (cap.4). In: FERNANDES, F. et al. Uso e Manejo do Lodo de Esgoto na Agricultura. Rio de Janeiro; PROSAB, Programa de Pesquisa em Saneamento Básico, 97p, 1999.

JENSEN, P.K.M.; PHUC, P.D.; KONRADSEN, F.; KLANK, L.T.; DALSGAARD, A. Survival of Ascaris eggs and hygienic quality of human excreta in Vietnamese composting latrines. Environmental Health, v.8, n.57, 2009.

JIMÉNEZ, B. Helminth ova control in sludge: a review. Water Science and Technology, v.56, n.9, p.147-155, 2007.

JIMÉNEZ, B.; WANG, L. Sludge treatment and management. In: UJANG, Z.; HENZE, M. (Eds.), Municipal Wastewater Management in Developing Countries: Principles and Engineering. IWA Publishing, 2006. 364p.

KELESSIDIS, A.; STASINAKIS, A.S. Comparative study of the methods used for treatment and final disposal of sewage sludge in European countries. Waste Management, v.32, n.6, p.1186-1195, 2012.

LU, Q.; HE, Z.L.; STOFFELLA, J. Land application of biosolids in the USA: A review. Applied and Environmental Soil Science, v.2012. 11p. 2012. doi:10.1155/2012/201462

MATOS, A.T. Práticas de Tratamento e Aproveitamento Agrícola de Resíduos Sólidos. Engenharia na Agricultura. Caderno didático: 45, Viçosa, Ed. Viçosa, 2008. 43p.

MAYA, C.; TORNER-MORALES, F.J.; LUCARIA, E.S.; HERN'ANDEZ, E.; JIM'ENEZ, B. Viability of six species of larval and nonlarval helminth eggs for different conditions of temperature, $\mathrm{pH}$ and dryness. Water Research, v.46, n.15, p.4770-4782, 2012.

METCALF \& EDDY. Wastewater Engineering: Treatment, Disposal and Reuse. $4^{\mathrm{a}}$ ed. New York, McGraw - Hill Book, 2003. 1815p. 
MEYER, K.B.; MILLER, K.D.; KANESHIRO, E.S. Recovery of Ascaris eggs from sludge. Journal Parasitology, v.64, n.2, p.380-383, 1978.

PINTO, M.A.T. Higienização de lodos. In: ANDREOLI, C.V.; VON SPERLING, M.; FERNANDES. F. Lodos de esgotos: tratamento e disposição final. Belo Horizonte: DESA/UFMG, SANEPAR, 2001. p.261-297.

R DEVELOPMENTCORE TEAM. $R$ : A language and environment for statistical computing. $R$ Foundation for Statistical Computing, Vienna, Austria, 2008. 1706p.

SINHA, R. K.; HERAT, S.; BHARAMBE, G.; BRAHAMBHATT, A. Vermistabilization of sewage sludge (biosolids) by earthworms: converting a potential biohazard destined for landfill disposal into a pathogen-free, nutritive and safe biofertilizer for farms. Waste Management \& Research, v.28, n.10, p.872-881, 2010.

SPINOSA, L. Wastewater sludge: A global overview of the current status and future prospects. IWA Publishing, UK, 2011, p.11-15.

STRAUSS, M.; DRESCHER, S.; ZURBRÜGG, C.; MONTANGERO, A.; CONFIE, O.; DRECHSEL, P. Co-composting of Faecal Sludge and Municipal Organic Waste - A Literature and State-of-Knowledge Review. Swiss Federal Institute of Environmental Science and Technology (EAWAG). 2003. 50p.

TRÖNNBERG， L.; HAWKSWORTH， D.; HANSEN, A.; ARCHER, C.; STENSTRÖM, T. A. Household-based prevalence of helminths and parasitic protozoa in rural KwaZulu-Natal, South Africa, assessed from faecal vault sampling. Transactions of the Royal Society of Tropical Medicine and Hygiene, v.104, n.10, p.646-652, 2010.

U.S. EPA. Control of pathogens and vector attraction in sewage sludge, including domestic septage, under 40 CFR part 503: Environmental Regulations and Technology. EPA/625/R-92/013, U.S. Environmental Protection Agency, Ohio, USA, 2003. 186p.

VELOSO, C.A.C.; BORGES, A.L.; MUNIZ, A.S.; VEIGAS, I.A.J.M. Efeito de diferentes materiais no $\mathrm{pH}$ do solo. Scientia Agricola, v.49, n.1, p.123128, 1992.

WHO. Guidelines for the safe use of wastewater, excreta and greywater. In: Policy and Regulatory Aspect, v.1. World Health Organization, Geneva. 2006. 100p. 